\title{
Inactivation of Mycobacteria by Radicals from Non-Thermal Plasma Jet ${ }^{\text {S }}$
}

\author{
Chaebok Lee ${ }^{1,2}$, Bindu Subhadra ${ }^{1,2}$, Hei-Gwon Choi ${ }^{1}$, Hyun-Woo Suh ${ }^{2}$, Han. S Uhm ${ }^{3}$, and Hwa-Jung Kim ${ }^{1,2^{*}}$ \\ ${ }^{1}$ Department of Medical Science, Chungnam National University, Daejeon 35015, Republic of Korea \\ ${ }^{2}$ Department of Microbiology, College of Medicine, Chungnam National University, Daejeon 35015, Republic of Korea \\ ${ }^{3}$ New Industry Convergence Technology RED Center, Ajou University, Suwon 16499, Republic of Korea
}

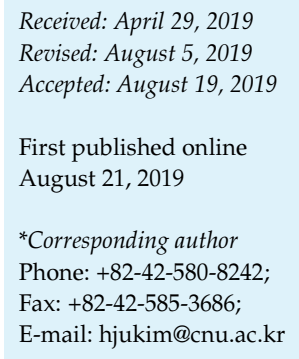

S upplementary data for this paper are available on-line only at http://jmb.or.kr.

pISSN 1017-7825, eISSN 1738-8872

Copyright(C) 2019 by

The Korean Society for Microbiology and Biotechnology

\begin{abstract}
Mycobacterial cell walls comprise thick and diverse lipids and glycolipids that act as a permeability barrier to antibiotics or other chemical agents. The use of $\mathrm{OH}$ radicals from a non-thermal plasma jet (NTPJ) for the inactivation of mycobacteria in aqueous solution was adopted as a novel approach. Addition of water vapor in a nitrogen plasma jet generated $\mathrm{OH}$ radicals, which converted to hydrogen peroxide $\left(\mathrm{H}_{2} \mathrm{O}_{2}\right)$ that inactivated non-pathogenic Mycobacterium smegmatis and pathogenic Mycobacterium tuberculosis H37Rv. A stable plasma plume was obtained from a nitrogen plasma jet with $1.91 \mathrm{~W}$ of power, killing Escherichia coli and mycobacteria effectively, whereas addition of catalase decreased the effects of the former. Mycobacteria were more resistant than E. coli to NTPJ treatment. Plasma treatment enhanced intracellular ROS production and upregulation of genes related to ROS stress responses (thiolrelated oxidoreductases, such as SseA and DoxX, and ferric uptake regulator furA). Morphological changes of M. smegmatis and M. tuberculosis $\mathrm{H} 37 \mathrm{Rv}$ were observed after 5 min treatment with $\mathrm{N}_{2}+\mathrm{H}_{2} \mathrm{O}$ plasma, but not of pre-incubated sample with catalase. This finding indicates that the bactericidal efficacy of NTPJ is related to the toxicity of $\mathrm{OH}$ and $\mathrm{H}_{2} \mathrm{O}_{2}$ radicals in cells. Therefore, our study suggests that NTPJ treatment may effectively control pulmonary infections caused by $M$. tuberculosis and nontuberculous mycobacteria (NTM) such as M. avium or M. abscessus in water.
\end{abstract}

Keywords: Non-thermal plasma, hydroxyl radical, ROS stress, Mycobacteria

\section{Introduction}

Mycobacterium tuberculosis (Mtb) is an obligate human pathogen that causes tuberculosis. Nontuberculous mycobacteria (NTM), including M. avium, M. kansasii, and M. abscessus, are opportunistic pathogens that are frequently isolated from diverse environments such as water, soil, and tap water [1]. It is important to inactivate these pathogens present in the environment for prevention of the chronic pulmonary diseases which they cause. In both, gramnegative and gram-positive cells, a common mechanism of cellular death inflicted by bactericidal antibiotics is by the generation of $\mathrm{OH}$ radicals via Fenton's reaction [2]. It has been reported that rifampin-induced hydroxyl radicals participate at least partially, in killing Mtb [3], and that Mtb is extraordinarily susceptible to vitamin C-mediated $\mathrm{OH}$ radicals [4].

The ability of $\mathrm{OH}$ radicals to induce biological damage is often exploited in the medical fields as therapeutic tools. Among these, reactive oxygen species (ROS) generated by non-thermal atmospheric-pressure plasma are an important means of inactivating microbial pathogens $[5,6]$. More recently, the efficiency of the cold argon plasma jet and dielectric barrier discharge to inactivate mycobacteria were reported [7, 8]. They determined the size of growth inhibition in the solid medium and reported that the dielectric barrier discharge was an effective method. There is no study on oxidative stress by radicals in nitrogen plasma jet with mycobacteria in media. Atmosphericpressure plasma jets produce short-lived reactive species, 
such as $\mathrm{OH}$ radicals, including atomic oxygen and nitric oxide $[9,10]$. These devices are compact and structurally flexible with low discharge power, and have been applied in biological and medical fields [11-13]. Such devices have been employed to inactivate Staphylococcus, Streptococcus, and even bacterial endospores [14-16]. However, the mycobacterial cell wall is much thicker than that in other gram-negative bacteria, and it also differs from other bacterial cells in biochemical composition [17]. In order to exert antimicrobial effects on Mtb by NTPJ, the plasma condition should be more efficient $[9,10,18]$. Production of $\mathrm{OH}$ radicals and hydrogen peroxide through our NTPJ device should be at low plasma dose, or enough to kill or inactivate bacteria. Control of this plasma dose can be a critical requirement for the development of an efficient plasma sterilizer [18].

We investigated the inactivating effect of plasma jets with $\mathrm{N}_{2}$ gas alone, or a gas-mixture composed of $\mathrm{N}_{2}$ and distilled water vapor on mycobacteria in aqueous solution. We found that the mycobacteria were more resistant than E. coli to NTPJ. The NTPJ with $\mathrm{N}_{2}+\mathrm{H}_{2} \mathrm{O}$ gas was more effective in generating the radicals and inactivating mycobacteria compared to $\mathrm{N}_{2}$ gas alone. Plasma treatment induced intracellular ROS production and enhanced the expression of genes related to ROS in mycobacteria. Catalase significantly inhibited the responses generated by the plasma. The hydroxyl radicals generated by NTPJ are converted to hydrogen peroxide, which leads to antimicrobial effects, eventually resulting in gradual death of bacteria.

\section{Materials and Methods}

\section{Non-Thermal Plasma Jet (NTPJ) Device}

A discharge power at frequency, $f=60 \mathrm{~Hz}$ obtained from a high-voltage AC power supply, was passed through an electrode, and eventually fed into the plasma jet source (Fig. 1A). The glove box was vacuumed to eliminate any involvement of oxygen, and purged with pure nitrogen gas before the experiment. To generate plasma, $\mathrm{N}_{2}$ gas alone or a mixture of $\mathrm{N}_{2}$ and distilled water vapor, was introduced through a mass controller (MFC, ATOVAC1200). This device regulated the flow rate of $\mathrm{N}_{2}$ gas at $600 \mathrm{cc} / \mathrm{min}$ (when $\mathrm{N}_{2}$ gas alone was passed) and a flow rate of $400 \mathrm{cc} / \mathrm{min}$, when $\mathrm{N}_{2}$ gas was passed through the water-bottle vapor gas. The plasma jet source used in this study had a needle structure (Fig. 1B) made of stainless steel $(1.3 \mathrm{~mm}$ in inner diameter and $0.3 \mathrm{~mm}$ thickness). Plasma was generated in the porous alumina-based ceramics between the electrodes, which were separated by a gap of $1 \mathrm{~mm}$ [19]. Nitrogen was injected into the electrode and ejected through the 1-mm hole in the outer electrode via the porous layers. The input power led to the generation of a large number of pulses
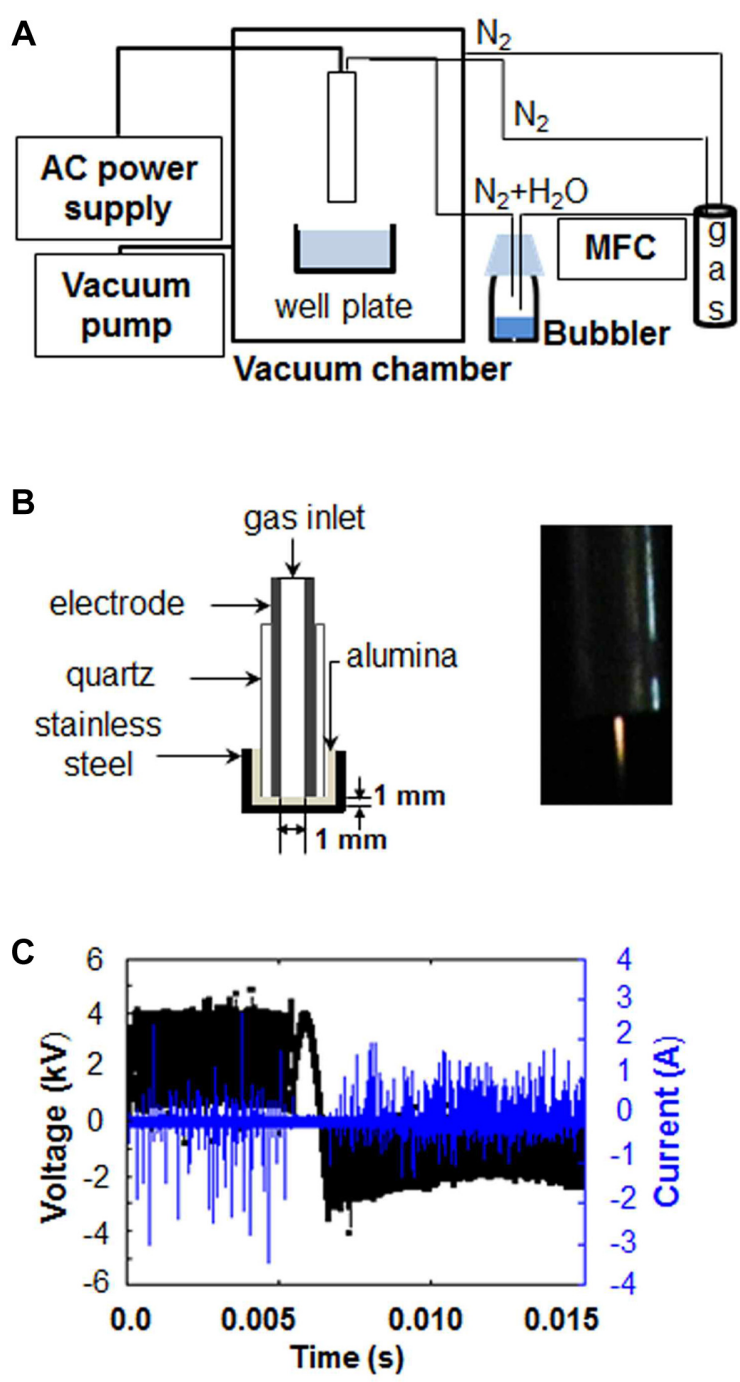

Fig. 1. (Color online) Non-thermal plasma jet device with bubbler (A) Schematic view of a non-thermal plasma generation system, (B) Schematic view (left panel), and picture (right panel) of nitrogen-plasma jet source, and (C) Voltage and current waveforms of the nitrogen-plasma jet, $\mathrm{Vrms}=2.15 \mathrm{kV}$ and $\operatorname{Im}=0.89 \mathrm{~mA}$.

(Fig. 1C), accompanied by a subsequent decrease in Vrms to $2.15 \mathrm{kV}$ (TDS2002C, Tektronix), and an increase in current, $\mathrm{I}_{\mathrm{m}}$, to $0.89 \mathrm{~mA}$ (P6021, Tektronix), corresponding to a 1-slm (standard liter per min) plasma jet (inset photograph, Fig. 1B) in the $\mathrm{N}_{2}+\mathrm{H}_{2} \mathrm{O}$ gas mixture. Optical spectroscopy of the discharge was performed using a spectrometer (Ocean Optics, HR4000, USA) at $0.7 \mathrm{~nm}$ resolution. The detailed design and function of NTPJ has been previously reported [19].

Bacteria Strains, Culture Conditions and Colony Assay

The slowly growing Mycobacterium tuberculosis H37Rv (ATCC 
27294) and rapidly growing Mycobacterium smegmatis (Msm, ATCC 700084) were purchased from American Type Culture Collection (ATCC, Manassas,VA). The mycobacteria were grown at $37^{\circ} \mathrm{C}$ in $7 \mathrm{H} 9$ (BD Difco) supplemented with $10 \%$ OADC (Albumin bovine serum, vol/vol) and $0.2 \%$ glycerol. Escherichia coli (NCCP 14762) were cultured in Luria Bertani Broth until they reached the logarithmic growth phase. The cultured bacteria were diluted to $1 \times 10^{5}$ cells $/ \mathrm{ml}$ and $1 \times 10^{7}$ cells $/ \mathrm{ml}$ and $0.5 \mathrm{ml}$ of the diluted bacterial solution was added to a 24-well plate (30024, SPL), and treated with the plasma jet. The bacteria after plasma exposure were serially diluted 10-fold in DPBS (LB001-02, Welgene) media, and colony assay was performed on 7H10 agar plates.

\section{$\mathrm{pH}$, Temperature and Radical Concentrations}

Around $0.5 \mathrm{ml}$ of $7 \mathrm{H} 9$ in a 24-well plate was treated with an NTPJ with $\mathrm{N}_{2}$ alone and with a mixture of water and $\mathrm{N}_{2}$ for 1,3 , and $5 \mathrm{~min}$. The $\mathrm{pH}$ and radical concentration of each sample were measured immediately after plasma exposure. The $\mathrm{pH}$ was measured using a pH meter (Orion Star A211, Thermo Scientific) and the concentrations of hydrogen peroxide and nitrite in the 7H9 media were analyzed using a Quantichrom Peroxide Assay Kit (DIOX-250, BioAssay Systems) and Griess reagent, respectively. In order to verify the decomposition of $\mathrm{H}_{2} \mathrm{O}_{2}$, catalase, which is used to scavenge the hydrogen peroxide, was used. The cells were pre-incubated with the catalase for $15 \mathrm{~min}$ at room temperature and then treated with plasma. From $300 \mathrm{kU} / \mathrm{ml}$ of catalase solution (C3556, Sigma-Aldrich), $1.5 \mathrm{kU} / \mathrm{ml}$ was used. $\mathrm{OH}$ radicals were also measured using terephthalic acid (TA, Sigma-Aldrich). Ten millimolars of TA was prepared in $5 \mathrm{mM} \mathrm{NaOH}$. Five millimolars of TA was added to 7H9 media, and fluorescence was measured at an excitation/emission of 310/425 nm (Synergy H1, Biotek) [20]. For temperature measurement, plasma was exposed to the center of the $7 \mathrm{H} 9$ well plate, maintaining a gap of $5 \mathrm{~mm}$ from the plasma source end. Immediately after plasma exposure, the center of the well plate was measured using FLIR (BCAM SD infrared thermal imager).

\section{LIVE/DEAD BacLight Bacterial Viability Assay}

Viability was determined using the BacLight Bacterial Viability
Kit (L7012, Thermo Fisher, USA) according to the manufacturer's protocol. Briefly, $3 \mu \mathrm{l}$ of live/dead staining solution was added to $997 \mu \mathrm{l}$ of cell suspension. The stained bacteria were then analyzed by confocal laser scanning microscopy (TCS SP8, Leica, Germany). Images of the mycobacteria were acquired using Leica LAS $X$ software (Leica Microsystems).

\section{Measurement of Intracellular ROS}

To detect intracellular ROS, cells were stained with $10 \mu \mathrm{M}$ $\mathrm{H}_{2}$ DCFDA (C6827, Life Technologies) for $30 \mathrm{~min}$ at $37^{\circ} \mathrm{C}$ in the dark, and the cells were then incubated in PBS at $37^{\circ} \mathrm{C}$ for $1 \mathrm{~h}$ for recovery. ROS were measured using a microfluorescence reader (Fluoroskan Ascent, Thermo Scientific) at 488/533 (Ex/Em) nm.

\section{Total RNA Extraction}

NTPJ-treated Mtb H37Rv was resuspended in $1 \mathrm{ml}$ of Trizol reagent (Life Technologies) and then sonicated at $20 \mathrm{kHz}$ for $5 \mathrm{~min}$ (Pulse on: 5 s, Pulse off: 5 s, Amp: 32\%) in an ice box [21]. After $10 \mathrm{~min}$ of incubation at $37^{\circ} \mathrm{C}, 0.5 \mathrm{ml}$ of chloroform was added to the Trizol reagent mixture and mixed vigorously for $15 \mathrm{~s}$. The cell debris was removed by centrifugation at $10,000 \times g$ for $10 \mathrm{~min}$ at $4^{\circ} \mathrm{C}$, and the upper aqueous phase solution was collected in a new tube. Then, $0.5 \mathrm{ml}$ of isopropanol was added to the aqueous phase and incubated at RT for $10 \mathrm{~min}$. RNA was precipitated by centrifugation at $13,000 \times \mathrm{g}$ for $15 \mathrm{~min}$ at $4^{\circ} \mathrm{C}$. The RNA pellet was washed twice with $70 \%$ ethanol, air-dried for $15 \mathrm{~min}$, and then resuspended in $40 \mu \mathrm{l}$ of DEPC (diethyl pyrocarbonate)-treated water. RNA concentration and purity (A260/A280 nm) were measured using NanoDrop (ND-1000, Qiagen). The total RNA was converted to cDNA using Cyclescript RT Premix (dT20, Bioneer), according to the manufacturer's protocol. The synthesized cDNA was used for real-time PCR (Biomera, UNO Thermoblock).

\section{Quantitative Real-Time PCR (qRT-PCR)}

Two-step qRT-PCR was performed with cDNA samples using the Rotor-gene SYBR Green PCR Master Mix (204076, Qiagen). qRT-PCR was performed using the following thermal cycling conditions: initial heat activation at $95^{\circ} \mathrm{C}$ for $5 \mathrm{~min}$ followed by 40 cycles of $95^{\circ} \mathrm{C}$ for $10 \mathrm{sec}, 50^{\circ} \mathrm{C}$ for $20 \mathrm{sec}$, and $72^{\circ} \mathrm{C}$ for $15 \mathrm{sec}$ [22].

Table 1. Oligonucleotide Sequences in this study.

\begin{tabular}{lll}
\hline Oligonucleotide name & \multicolumn{1}{c}{ Sequence of oligonucleotide $\left(5^{\prime}-3^{\prime}\right)$} & \\
\hline RT 16S rRNA & F:TCC CGC GCC TTG TAC CC & R:CCA CTG GCT TCG GGT GTT A \\
RT katG & F:CCC ATG GCG CCG GCC CGG CC & R:CGA TGC CGC TGG TGA TCG CG \\
RT furA & F:AAA CGA TTT TCG GTG CCG TG & R:CGT CCA ACA GGA AGC CGT TA \\
RT ideR & F:AGT AAC CGT CGA AAC CAC CC & R:ACT TTC TCG ACC TTG ACC GC \\
RT bfrB & F:ATT TCC TCG TCG GCG AGC AGT TC \\
RT recA & F:ACG TCA AGT GTT CGA GGT CC & R:TCA CGT GCA ACG AAG TTC TC \\
RT SodA & F:ATG TCG ATT CCG GCA GAT CC & R:ACG TCA AGT GTT CGA GGT CC \\
RT DoxX & F:GCA CAT CTC GGG TCA GAT CA & R:CAG TGG AAC CAC CAC CGT TA \\
RT SseA & F:CCC ATA TGC CCG ATT ACC CC & R:CTT TTC GTT CAG CAA GAT CG \\
\hline
\end{tabular}

F: forward primers, R: reverse primers 
Relative gene expression was evaluated using the comparative cycle-threshold method. The mRNA level was normalized to that of 16S rRNA [23]. The primers used in this study are listed in Table 1.

\section{SEM Analysis}

For scanning electron microscopy (SEM, SU8230, Hitachi), the treated cells were fixed with $2.5 \%$ glutaraldehyde (Sigma-Adrich, 340855) in $0.1 \mathrm{M}$ phosphate buffer for $24 \mathrm{~h}$. The bacterial pellet was washed three times with phosphate buffer, and then fixed with $1 \%$ osmium tetroxide (Sigma- Aldrich, 75632) in $0.1 \mathrm{M}$ phosphate buffer for $1 \mathrm{~h}$ and dehydrated in a graded series of ethanol concentrations, and finally with $100 \%$ ethanol (3 times). The dehydrated pellets were dried in a critical point dryer (EM CPD300, Leica) at room temperature and coated with gold (5 nm). SEM imaging was performed with Supra $60 \mathrm{VP}$.

\section{Statistical Analysis}

Statistical significance was determined using an unpaired Student's $t$-test. The $p$ value was obtained for comparison between the control and each treatment. $p<0.05\left(^{*}\right), p<0.01\left(^{* *}\right)$ and $p<$ $0.001(* *)$. ns; not significant.

\section{Results}

Physical Characteristics of the Plasma Generated by NTPJ with $\mathrm{N}_{2}+\mathrm{H}_{2} \mathrm{O}$ and $\mathrm{N}_{2}$ Gas

The discharged power and plasma components were analyzed. We found that a stable plasma plume was obtained with power of less than $1.91 \mathrm{~W}$, which was dissipated in the discharge (Fig. 1C). Next, ROS produced in the ambient air by plasma jets with $\mathrm{N}_{2}$ alone, and $\mathrm{N}_{2}+\mathrm{H}_{2} \mathrm{O}$ gas were measured. The emission intensity of $\mathrm{OH}$ radicals with the addition of $1.16 \%$ in $\mathrm{N}_{2}$, showed peaks at $306.79 \mathrm{~nm}$ and $309.36 \mathrm{~nm}$, while the peak intensities were significantly lower for $\mathrm{N}_{2}$ gas alone (Fig. 2A). The emission spectrum of the pure nitrogen plasma contained $\mathrm{NO}$ radicals and $\mathrm{N}_{2}$ second-positive system (SPS) only (Fig. 2B). The more dominant $\mathrm{OH}$-related spectra appeared when water vapor was added. We further confirmed the efficiency of our device by determining E. coli survival. Because the nutrients present in the growth media act as scavengers for ROS, E. coli was resuspended in PBS, treated with plasma jets, and thereafter, immediately plated on LB agar. E. coli $\left(10^{5}\right)$ was completely killed after 1 min of treatment (Fig. 2C). The plasma flame discharged by $\mathrm{N}_{2}+\mathrm{H}_{2} \mathrm{O}$ gas killed the bacteria more effectively than that by $\mathrm{N}_{2}$ gas alone.

\section{Plasma Characteristics in the Mycobacterial Culture Media}

We next investigated the physicochemical properties of
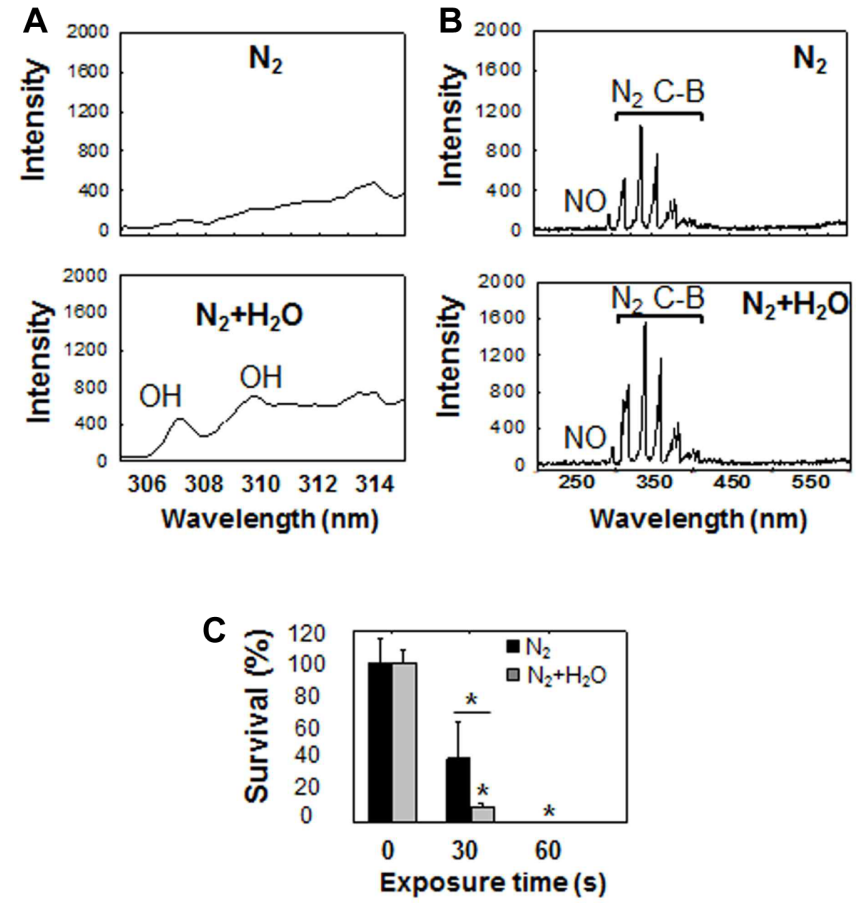

Fig. 2. (Color online) Optical emission spectra (OES) of a plasma jet with $\mathrm{N}_{2}+\mathrm{H}_{2} \mathrm{O}$ and $\mathrm{N}_{2}$ gas and colony count assay, shows that plasma inactivates E.coli rapidly in a timedependent manner.

(A) In the ranges of 305-315 nm, (B) 200-600 nm. A higher intensity of $\mathrm{OH}$ radicals is detected with the addition of water vapor. (C) Relative survival shows that NTPJ treatment inactivated E. coli $(5 \times$ $10^{4}$ cells $/ 0.5 \mathrm{ml}$ ) rapidly; the percentage of surviving cells was normalized to that of the untreated cells. The values are mean \pm SD (standard deviation) for three replicates, $p<0.05\left(^{*}\right)$. Unpaired Student's $t$-test was performed between the $\mathrm{N}_{2}$ and $\mathrm{N}_{2}+\mathrm{H}_{2} \mathrm{O}$ treatment. $p<0.05\left(^{*}\right)$.

the plasma-treated 7H9 media, the liquid media used for mycobacterial culture. Changes in temperature, $\mathrm{pH}$, and radical concentrations in the culture, after treatment, were measured. When the distance between the sample and plasma exit was $5 \mathrm{~mm}$, temperature of the area measured by FLIR (BCAM SD infrared thermal imager) after plasma treatment, was between $17.6^{\circ} \mathrm{C}$ and $36^{\circ} \mathrm{C}$, depending on the exposure time (Fig. 3A); the media treated by $\mathrm{N}_{2}+\mathrm{H}_{2} \mathrm{O}$ plasma showed slightly lower temperature as compared to the media treated by $\mathrm{N}_{2}$-only plasma. There were no significant changes in the $\mathrm{pH}$ of the media, before or after NTPJ treatment with $\mathrm{N}_{2}+\mathrm{H}_{2} \mathrm{O}$ or $\mathrm{N}_{2}$ gas alone (Fig. 3B). The intensities of $\mathrm{OH}$ radicals, hydrogen peroxide concentration, and nitrite concentration in the culture media, which play important roles in bacterial inactivation, were increased 
A
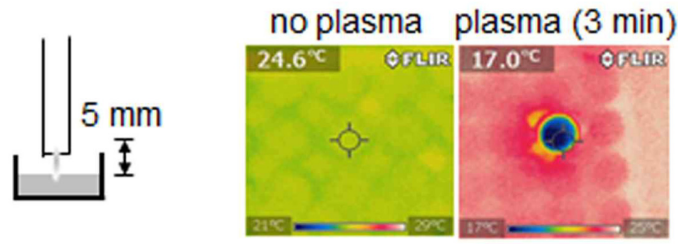

C

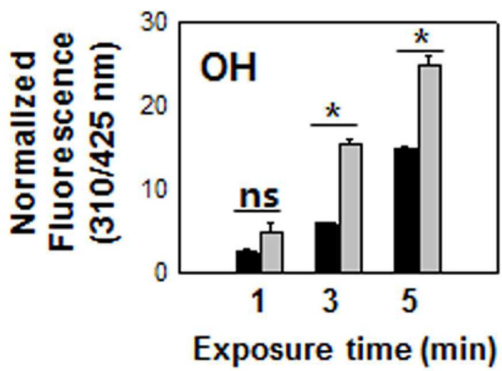

- $\mathrm{N}_{2} \quad \square \mathrm{N}_{2} / \mathrm{H}_{2} \mathrm{O}$

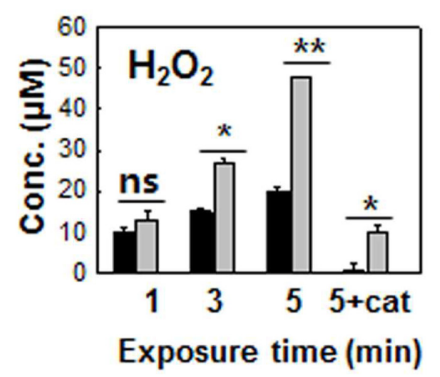

B

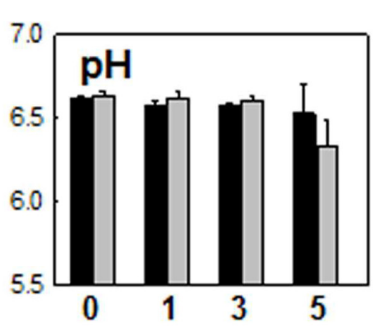

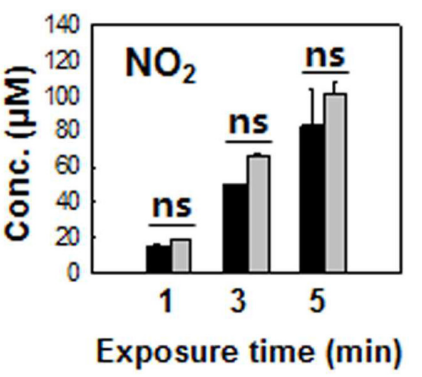

Fig. 3. (Color online) Changes in the temperature, $\mathrm{pH}$ and radical concentrations after NTPJ treatment with $\mathrm{N}_{2}+\mathrm{H}_{2} \mathrm{O}$ and $\mathrm{N}_{2}$ gas in 7H9 medium.

(A) Plasma treatment set-up and FLIR thermal image of the 24-well plate surface without exposure (left) and after plasma treatment (right). Colors shown in the images represent the relative temperature of the water surface; the temperature range corresponds to the colors (blue through red) on the color bar shown at the bottom of each image. Temperature of the central region of the well plate is indicated at the upper left corner of each image, (B) $\mathrm{pH}$, and (C) $\mathrm{OH}$ radical intensity (fluorescence intensity was normalized to that of the untreated samples), $\mathrm{H}_{2} \mathrm{O}_{2}$ concentration, and nitrite concentration, after NTPJ treatment with $\mathrm{N}_{2}+\mathrm{H}_{2} \mathrm{O}$ and $\mathrm{N}_{2}$ gas alone, for 1,3, $5 \mathrm{~min}$, and with $1.5 \mathrm{kU}$ catalase for $5 \mathrm{~min}$, in $7 \mathrm{H} 9$ media. Error bars represent the SD. $n=3$. Unpaired Student's $t$-test was performed between the $\mathrm{N}_{2}$ and $\mathrm{N}_{2}+\mathrm{H}_{2} \mathrm{O}$ treatment. $p<0.05\left(^{*}\right)$ and $p<0.01\left({ }^{* *}\right)$. ns, not significant.

with a corresponding increase in the NTPJ exposure time (Fig. 3C). Nitric monoxide (NO) radicals from NTPJ may be converted to nitrite $\left(\mathrm{NO}_{2}\right)$, which reacts with oxygen in cells and media [24]. Generation of radicals by $\mathrm{N}_{2}+\mathrm{H}_{2} \mathrm{O}$ plasma was significantly higher than that by $\mathrm{N}_{2}$ plasma, except for $\mathrm{NO}_{2}$. In a parallel experiment, we conducted catalase enzyme scavenging tests in which the production of hydrogen peroxide was significantly decreased by incubation with catalase before plasma treatment (Fig. 3C). Collectively, these results suggest that ROS from $\mathrm{N}_{2}+\mathrm{H}_{2} \mathrm{O}$ plasma are generated in significant amounts in $7 \mathrm{H} 9$ media.

\section{The Effect of NTPJ Treatment with $\mathrm{N}_{2}+\mathrm{H}_{2} \mathrm{O}$ Gas and $\mathrm{N}_{2}$ Gas Alone, on Mycobacterial Inactivation}

Mycobacteria have a thick cell wall comprising diverse lipids and glycolipids, compared to other bacteria [17]. We compared the susceptibility of E. coli and rapidly growing nonpathogenic Msm to NTPJ treatment. Both bacteria were resuspended in PBS, followed by treatment with plasma. As shown in Fig. 4A, some of the Msm were found to survive even after $\mathrm{N}_{2}+\mathrm{H}_{2} \mathrm{O}$ plasma treatment for $2 \mathrm{~min}$, in contrast to E. coli, suggesting that Msm is more resistant to plasma. Next, the sterilizing effects of plasma, generated with $\mathrm{N}_{2}$ and $\mathrm{N}_{2}+\mathrm{H}_{2} \mathrm{O}$ gas, on Msm were investigated in the 7H9 mycobacterial culture medium. Msm, treated with NTPJ for the indicated time, were plated on 7H10 agar plates immediately (Fig. 4B), and at $24 \mathrm{~h}$ (Fig. 4C) after treatment to monitor their survival. As shown in Fig. 4B, approximately $20 \sim 40 \%$ of the Msm exposed to $\mathrm{N}_{2}$ gas plasma (depending on the time of exposure) were killed, while 25 75\% of the Msm exposed to plasma generated by $\mathrm{N}_{2}+\mathrm{H}_{2} \mathrm{O}$ gas, were killed, when immediately plated after exposure. However, it was observed that, when the bacteria were plated $24 \mathrm{~h}$ after exposure to $\mathrm{N}_{2}+\mathrm{H}_{2} \mathrm{O}$ plasma or $\mathrm{N}_{2}$ plasma for $5 \mathrm{~min}, 98 \%$ and $80 \%$ of the bacteria respectively, were killed (Fig. $4 \mathrm{C}$ ), indicating that plasmamediated bacterial killing effects were more apparent after $24 \mathrm{~h}$ incubation than immediately after plasma treatment. Also, samples that were preincubated with catalase before $\mathrm{N}_{2}+\mathrm{H}_{2} \mathrm{O}$ plasma exposure for $5 \mathrm{~min}$ showed increased 

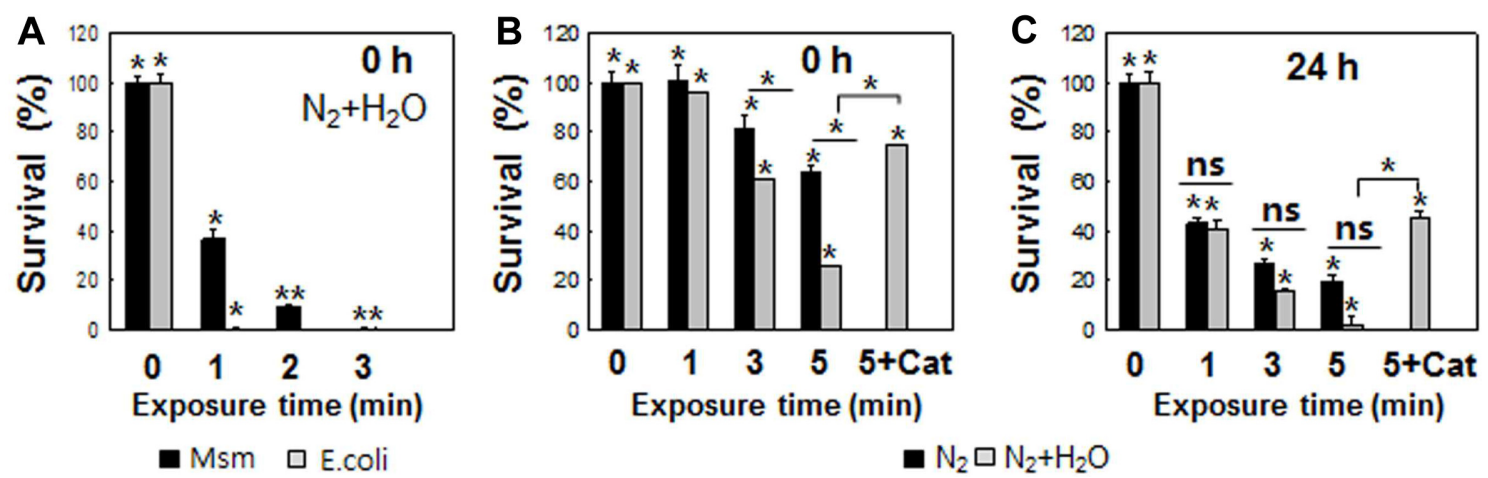

$\square \mathrm{N}_{2} \square \mathrm{N}_{2}+\mathrm{H}_{2} \mathrm{O}$

Fig. 4. (Color online) NTPJ with $\mathrm{N}_{2}+\mathrm{H}_{2} \mathrm{O}$ and $\mathrm{N}_{2}$ gas inactivates nonpathogenic Msm in a time-dependent manner.

(A) Relative survival of Msm versus E. coli immediately after NTPJ treatment with $\mathrm{N}_{2}+\mathrm{H}_{2} \mathrm{O}$ gas for $0,1,2$, and 3 min in PBS, (B) $0 \mathrm{~h}$, (C) $24 \mathrm{~h}$ after NTPJ treatment with $\mathrm{N}_{2}+\mathrm{H}_{2} \mathrm{O}$ and $\mathrm{N}_{2}$ gas for $0,1,3$, and $5 \mathrm{~min}$, and with catalase for $5 \mathrm{~min}$ in $7 \mathrm{H} 9$ media. CFU were plated immediately and at 24 $\mathrm{h}$ incubation after treatment on 7H10 solid media supplemented with ADS and were normalized to untreated. $n=3 . p<0.05\left(^{*}\right)$ and $p<0.01\left(^{(*}\right)$. Unpaired Student's $t$-test was performed between the $\mathrm{N}_{2}$ and $\mathrm{N}_{2}+\mathrm{H}_{2} \mathrm{O}$ treatment. $p<0.05\left(^{*}\right)$ and $p<0.01\left({ }^{*}\right)$. ns, not significant.

number of bacteria (Figs. 4B and 4C). We concluded that the decrease in the number of surviving bacteria is related to the oxidation of cells and that, the $\mathrm{N}_{2}+\mathrm{H}_{2} \mathrm{O}$ plasma jet effectively kills the $\mathrm{Mtb}$ cells through $\mathrm{OH}$ radicals and $\mathrm{H}_{2} \mathrm{O}_{2}$. Therefore, the effects of plasma generated with $\mathrm{N}_{2}+\mathrm{H}_{2} \mathrm{O}$ gas, on the inactivation of mycobacteria, were investigated in the subsequent experiments. We next investigated the sterilizing effects of plasma on pathogenic Mtb. The Mtb exposed to $\mathrm{N}_{2}+\mathrm{H}_{2} \mathrm{O}$ plasma for 5 min, were plated on $7 \mathrm{H} 10$ agar, immediately or after incubation for 1 to 3 days in $7 \mathrm{H} 9$ media. As shown in Fig. 5A, 70\% of the virulent Mtb H37Rv was killed immediately after treatment, but this proportion increased to $91 \%$ after $24 \mathrm{~h}$ incubation, when compared to the untreated control. There was no difference in the Mtb survival rate among the cells incubated for 1, 2, and 3 days after plasma treatment. The pretreatment of $\mathrm{Mtb}$ with catalase showed significantly more bacteria than in samples without catalase (Fig. 5A).

Intracellular ROS concentration is an important factor that exerts antimicrobial effects. Therefore, we estimated the intracellular ROS level of $\mathrm{Mtb}$, using the $\mathrm{H}_{2} \mathrm{DCFA}$ fluorescence dye assay (Fig. 5B). After plasma treatment for
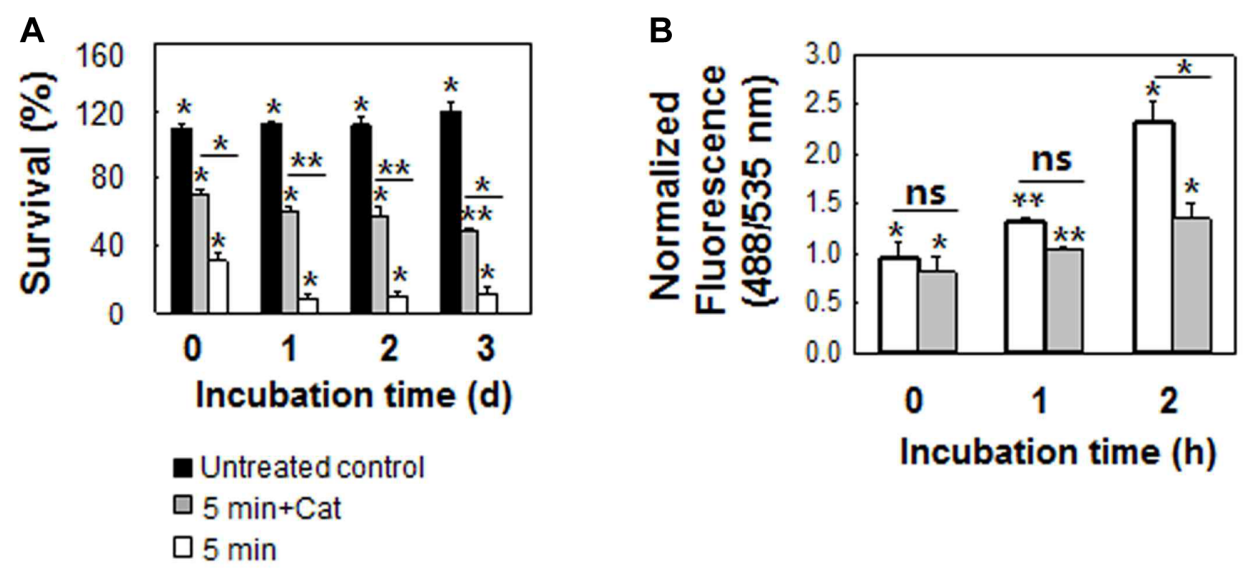

Fig. 5. (Color online) NTPJ with $\mathrm{N}_{2}+\mathrm{H}_{2} \mathrm{O}$ gas inactivates pathogenic Mtb $\mathrm{H} 37 \mathrm{Rv}$ cells.

(A) Relative survival was normalized to untreated cells at 0,1,2, and 3 days incubation, (B) ROS levels inside Mtb cells were measured using $\mathrm{H}_{2}$ DCFDA fluorescent dye in $7 \mathrm{H} 9$ growth media after NTPJ treatment for $5 \mathrm{~min}$ and with catalase for 5 min. Fluorescence was measured consecutively and was normalized to that of untreated cells. Error bars represent the SD. $n=3 . p<0.05(*)$ and $p<0.01(* *)$. Unpaired Student's $t-$ test was performed between $\mathrm{N}_{2}+\mathrm{H}_{2} \mathrm{O}$ plasma exposure for 5 min with pre-incubated catalase and $\mathrm{N}_{2}+\mathrm{H}_{2} \mathrm{O}$ treatment. $p<0.05\left(^{*}\right)$ and $p<0.01\left({ }^{* *}\right)$. ns, not significant. 
5 min, the ROS level within the Mtb cells was found to increase with a corresponding increase in incubation time. However, the increase in the ROS level within the Mtb cells was less apparent when catalase was added to the sample. At $2 \mathrm{~h}$ of incubation, the ROS level in the plasma-treated Mtb was increased by 2.3-folds, compared to that in the untreated $\mathrm{Mtb}$, and was significantly higher than that in the catalase-added samples. Therefore, these data suggest that $\mathrm{OH}$ radicals, generated by NTPJ, convert to hydrogen peroxide, which enhances intracellular ROS production, playing a role in killing of the bacteria.

\section{Plasma Treatment Disrupts Mycobacterial Wall Integrity}

We observed through SEM that radicals from a $\mathrm{N}_{2}+\mathrm{H}_{2} \mathrm{O}$ plasma clearly damaged cell-wall structure of the mycobacteria (Fig. 6). The cell-wall integrity was also found to be protected by the addition of catalase. There was no remarkable difference in plasma-mediated damage inflicted on non-pathogenic Msm and pathogenic Mtb. To further confirm the effect of plasma on bacteria, the $\mathrm{N}_{2}+$ $\mathrm{H}_{2} \mathrm{O}$ plasma-exposed Msm or Mtb were stained with the live/dead bacteria staining kit. Dead cells allow the entry of the impermeable PI dye, such that it binds DNA and emits red fluorescence. The untreated Msm and Mtb were stained green (Figs. S1 and 7). Msm were stained green immediately, after 3 min-treatment, however, those bacteria that were subjected to 5 min-treatment, stained red (Fig. S1). The bacteria that stained red and green simultaneously, showed yellow color in a merged plate, indicating that they were dying bacterial cells. Mtb treated with plasma for 5 min were stained red and green, but the number of dead bacteria stained with PI was significantly increased by plasma treatment compared to the untreated bacteria (Fig. 7). The number of red stained-bacteria decreases by pre-incubation with catalase before plasma exposure, in comparison to plasma treated-bacteria not incubated with catalase. Therefore, these data indicate that radicals generated by NTPJ may play a critical role in damaging the membranes and cell walls of mycobacterial cells.

\section{Expression of Genes Related to ROS Stress Responses in $\mathrm{N}_{2}+\mathrm{H}_{2} \mathrm{O}$ Plasma-Treated $\mathrm{Mtb}$}

To further understand the intra-bacterial responses to NTPJ, the expression of genes involved in the stress response against ROS in Mtb was analyzed by qRT-PCR. Because intracellular ROS were much higher after $2 \mathrm{~h}$ incubation than immediately after plasma exposure (Fig. 5B), total RNA from $\mathrm{N}_{2}+\mathrm{H}_{2} \mathrm{O}$ plasma-exposed Mtb was extracted after $2 \mathrm{~h}$ of incubation. Fig. $8 \mathrm{~A}$ indicates that

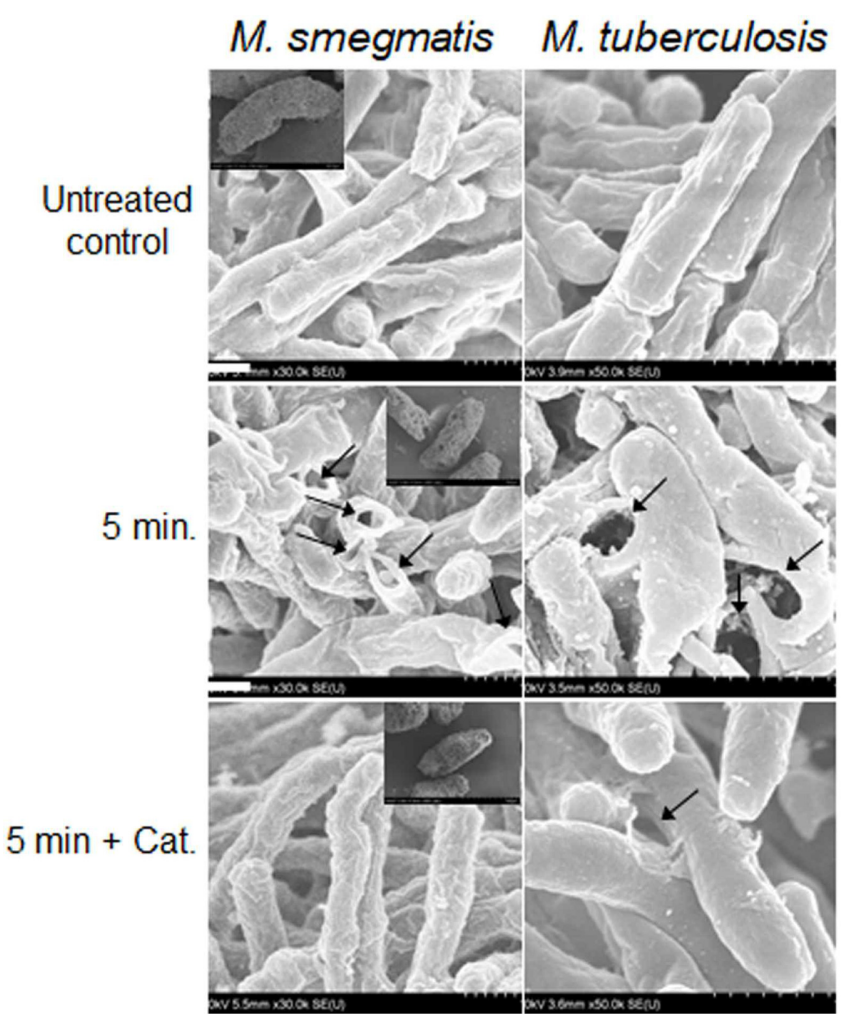

Fig. 6. (Color online) Effect of NTPJ with $\mathrm{N}_{2}+\mathrm{H}_{2} \mathrm{O}$ gas on mycobacterial wall integrity was evaluated by SEM.

Untreated cells, immediately after 5 min exposure, and cells exposed to a 5 min treatment under $\mathrm{N}_{2}+\mathrm{H}_{2} \mathrm{O}$ gas in the presence of catalase. NTPJ treatment enhances the disruption of the cell wall. The black arrows indicate the cell rupture of mycobacteria.

transcriptional response to plasma treatment is associated with detoxification of radicals through the membraneassociated oxidoreductase (SseA, DoxX, SseA) component of the cell membranes [25], which was enhanced compared to that in the untreated Mtb. SseA (thiol oxidoreductase, 9-fold) and DoxX (integral membrane protein, 6-fold) showed higher expression. In contrast, the expression of superoxide-detoxifying enzyme (SodA, 1.8), which is a major antioxidant in $\mathrm{Mtb}$, was much lower compared to that of DoxX and SseA. As expected, addition of catalase to the media before plasma exposure significantly decreased the plasma-mediated expression of these genes. As a positive control, $\mathrm{Mtb}$ treated with $\mathrm{H}_{2} \mathrm{O}_{2}$ showed a gene expression pattern similar to that obtained with plasma exposure (Fig. 8A). Moreover, the expression of SseA ( 21fold) and DoxX ( 8-fold) genes was enhanced with $\mathrm{H}_{2} \mathrm{O}_{2}$ $(0.1 \mathrm{mM})$ treatment, compared to that in the untreated $\mathrm{Mtb}$ cells. Additionally, we investigated the expression of several 


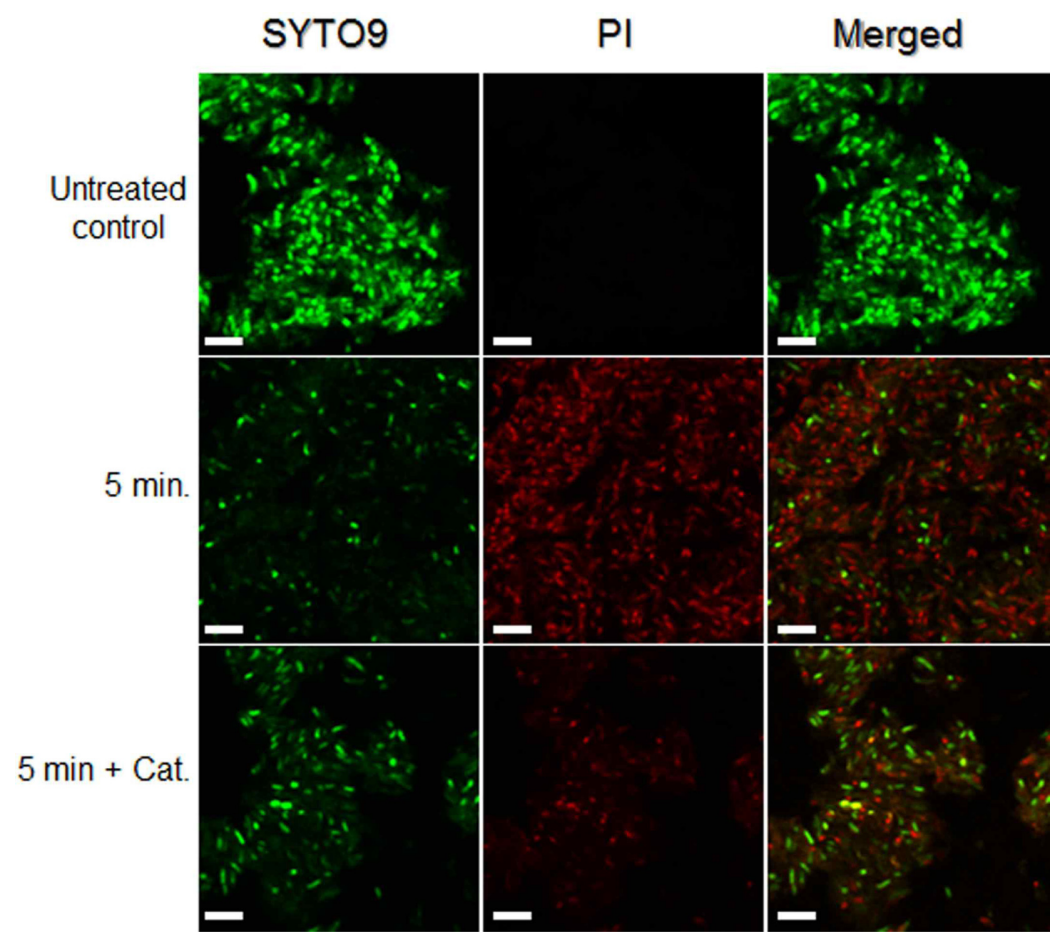

Fig. 7. (Color online) NTPJ with $\mathrm{N}_{2}+\mathrm{H}_{2} \mathrm{O}$ gas attacks the cell membrane in Mtb H37Rv cells and leads to gradual cell leakage. BacLight Live/Dead viability assay essentially tests the intact and damaged membranes in Mtb cells, and thus dying bacterial cells show yellow fluorescence, and dead cells show red fluorescence. The scale bar is $1 \mu \mathrm{M}$. Untreated cells, immediately after 5 min exposure, and exposure for 5 min with pre-incubated catalase. The column on the right shows the merged image of SYTO (green dye, Ex 480/500 nm) and PI (red, $490 / 635 \mathrm{~nm}$ ). The scale bar is $1 \mu \mathrm{M}$.

other genes related to iron regulation $($ fur $A$, ideR), iron storage $(b f r B)$, transcriptional regulation $(k a t G)$, and DNA repair (recA) in plasma exposed- or $\mathrm{H}_{2} \mathrm{O}_{2}$-treated-Mtb. $\mathrm{N}_{2}+\mathrm{H}_{2} \mathrm{O}$ plasma or $\mathrm{H}_{2} \mathrm{O}_{2}$ induced the expression of these tested genes in $\mathrm{Mtb}$ (Fig. 8B). Catalase also suppressed the plasma-mediated upregulation of these genes. Collectively, these results suggest that NTPJ enhances the expression of genes related to thiol oxidoreductase, iron-homeostasis, and stress responses in Mtb cells, indicating a need for detoxification.
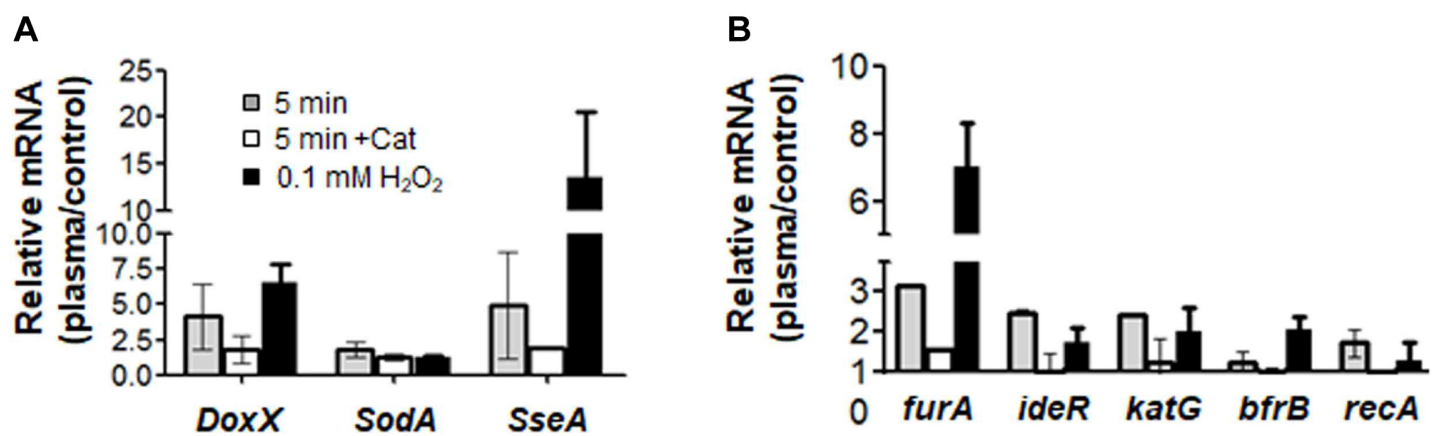

Fg. 8. (Color online) Identifying the defense systems against $\mathrm{ROS}$ in $\mathrm{N}_{2}+\mathrm{H}_{2} \mathrm{O}$ plasma jet.

Total mRNA was isolated using Trizol reagent, qRT-PCR analysis of Mtb cells at $2 \mathrm{~h}$ incubation after 5 min treatment, with catalase for $5 \mathrm{~min}$, and $0.1 \mathrm{mM} \mathrm{H}_{2} \mathrm{O}_{2}(2 \mathrm{~h})$ was performed. (A) Expression of membrane-associated reductase genes (DoxX, SodA, SseA) (B) Expression of iron homeostasis genes fur $A, i d e R$, and $b f r B$, transcriptional regulator gene $k a t G$, and DNA repair gene rec $A$. Data are representative of at least two different experiments performed in triplicate. Error bars show standard deviations from the mean. $n=3$. 


\section{Discussion}

Among the ROS, the hydroxyl $\mathrm{OH}$ is toxic to cells and causes cell death [26, 27], as bacteria do not contain scavenging enzymes for $\mathrm{OH}$ radicals [28]. More recently, it has been reported that $\mathrm{OH}$ radicals from a NTPJ also increase cell apoptosis, and showed selectivity between cancer cells and normal cells [29]. In this study, we found that the plasma generated by a NTPJ device effectively inactivated mycobacteria. Another report showed that E. coli was completely inactivated for $60 \mathrm{sec}$ exposure to floating-electrode dielectric-barrier discharge (FE-DBD) [30]. The Mtb cell envelop differs substantially from the cell wall structure of common bacteria and is a highly lipophilic barrier that contributes to resistance against common antibiotics [31]. It is well known that the lipid content of Mtb constitutes about $60 \%$ of the dry weight of the bacteria. Therefore, mycobacteria are more resistant to plasma than E. coli, as shown in Fig. 4A. We have clearly demonstrated that the plasma jet device generates a stable plasma jet with micro-discharges in a porous layer [10]. As shown in Fig. 1C, we were able to obtain a stable plasma jet at $1.91 \mathrm{~W}$, through the generation of steady discharge voltage and current pulses during plasma discharge. The process temperature of the plasma jet was $17-36^{\circ} \mathrm{C}$ during the time-dependent treatment, indicating that heat is not the only factor responsible for effective antibacterial action. Further, we demonstrated that $\mathrm{OH}$ radical production is higher when a mixture of $\mathrm{H}_{2} \mathrm{O}$ and $\mathrm{N}_{2}$ is used in the plasma jet, compared to $\mathrm{N}_{2}$ alone [19]. In this study, the plasma jet containing a mixture of $1.16 \% \mathrm{H}_{2} \mathrm{O}$ and $\mathrm{N}_{2}$, produced more dominant $\mathrm{OH}$ radicals compared to that with $\mathrm{N}_{2}$ alone, as indicated by the more effective bactericidal activity demonstrated against E. coli and mycobacteria.

To further understand the antimicrobial activity of ROS $\left(\mathrm{OH}\right.$ and $\left.\mathrm{H}_{2} \mathrm{O}_{2}\right)$ in mycobacteria, we investigated if there was a change in intracellular ROS concentration after plasma treatment. We observed that after $2 \mathrm{~h}$ incubation, intracellular ROS were increased by 2.3 fold (Fig. 5B). It is reported that intracellular concentrations of hydrogen peroxide (less than $1 \mu \mathrm{M}$ ) are toxic for E. coli [32]. We envisage that the hydrogen peroxide produced $(48 \mu \mathrm{M}$ concentrations, Fig. 3C) in growing media, diffuses in the water, penetrating and interacting with Mtb cells inside the media. The hydrogen peroxide exhibits strong antibacterial properties by inducing thiol oxidation, which subsequently damages enzymes and proteins [33, 34]. We therefore conclude that stress due to hydrogen peroxide can enhance the rate of bacterial inactivation. Our finding that the sterilizing effect of $\mathrm{N}_{2}+\mathrm{H}_{2} \mathrm{O}$ plasma on Mtb cells in growth media was more substantial after $24 \mathrm{~h}$ rather than immediately (Fig. 4B), further suggests that ROS production in plasma persists over the course of time to trigger bactericidal activity inside the mycobacterial cells (Figs. 4C and 5A).

ROS generated in plasma directly attack microbial DNA, lipids, and proteins in cell membranes, leading to cell damage [35]. Plasma treatment enhances expression of genes related to ROS stress in bacteria [36], however, there is no report on the effect of plasma-induced radicals on the expression of SseA and DoxX during detoxification of bacteria. In this study, significant up-regulation of SseA and DoxX were observed in mycobacteria (Fig. 8A). The major role of SseA and DoxX is to promote resistance to ROS stress that disrupts cytosolic thiol homeostasis [25], whereas SodA does not directly influence thiol recycling; however, this protein is a key player in thiol homeostasis as a component of the membrane-associated oxidoreductase complex (MRC). Our data also showed that SodA was not strongly enhanced, suggesting that ROS may affect thiol homeostasis. Optical spectroscopy data showed that the plasma jet did not generate superoxide radicals $\left(\mathrm{O}_{2}^{-}\right)$, therefore, we can speculate that the hydroxyl radicals from the plasma jet cause the formation of hydrogen peroxide, which then oxidizes iron-sulfur (Fe-S) proteins, resulting in increased ferrous ion concentration. Notably, the ferric uptake regulator, fur $A$, was more enhanced compared to other genes (ideR, bfrB, katG) after NTPJ treatment (Fig. 8B). It may be envisaged that an increased production of ferrous ions results in the generation of reactive oxygen species, which in turn, triggers the detoxification of cells. In line with our finding, many studies have reported the involvement of iron-regulation genes (fur $A$, ideR) in detoxification of exogenous or endogenous oxidants [37, 38]. In this regard, $\mathrm{OH}$ radicals play a critical role in antibacterial activity of mycobacteria. In the current study, $0.1 \mathrm{mM} \mathrm{H}_{2} \mathrm{O}_{2}$ treatment also confirmed a similar pattern of up-regulation of genes such as DoxX, SseA, and furA which are important players in promoting resistance to ROS stress.

In our study, membrane leakage was observed (Figs. 6 and 7) when water vapor was used in the plasma discharge, suggesting that ROS in plasma interact with the membranes of the Mtb cell wall which are their primary cell barrier, inducing loss of membrane integrity. Taken together, these data suggest that the $\mathrm{OH}$ radicals, generated by NTPJ, convert to ROS within the bacteria and play a bactericidal role.

The NTPJ device used in this study was specifically 
designed for production of large amounts of hydroxyl radicals and hydrogen peroxide. The OES results (Figs. 2A$2 \mathrm{~B}$ ) suggest that $\mathrm{NO}$ radicals, $\mathrm{OH}$ radicals, and the $\mathrm{N}_{2}$ second-positive system (SPS) were significantly produced, but the generation of $\mathrm{OH}$ radicals is much more compared to $\mathrm{NO}$ radicals. The excited nitrogen molecules in a metastable level of $\mathrm{N}_{2}\left(\mathrm{~A}_{3} \Sigma_{\mathrm{u}}{ }^{+}\right)$dissociate water molecules, and generate hydroxyl radicals and hydrogen atoms, which is one of the most important reactive species $[6,19]$. Plasma discharge in the nitrogen gas mixed with water molecules produces $\mathrm{NH}$ radicals, but the density of $\mathrm{NH}$ radicals is 5 orders in magnitude less than the hydroxyl density [39], indicating that hydroxyl in the nitrogen plasma dominates over other species except hydrogen peroxides. The hydrogen peroxide density is one order of magnitude higher than the hydroxyl density [39]. The results of this study are meaningful for pulmonary-disease control in the biomedical field. The NTPJ treatment sterilizes effectively NTM species in water such as M. avium, M. intracellulare, and M. abscessus, which are responsible for pulmonary disease infections.

In summary, this is the first study to report the application of NTPJ in mycobacterial inactivation. Using $1 \mathrm{slm}$ of nitrogen-water vapor $(1.16 \%)$ gas flow and $1.91 \mathrm{~W}$ of discharge power at atmospheric pressure, we obtained a stable plasma jet for efficient sterilization. The plasma jet with $\mathrm{N}_{2}+\mathrm{H}_{2} \mathrm{O}$ gas killed the bacteria more effectively than that with $\mathrm{N}_{2}$ gas only. The $\mathrm{OH}$ radicals generated by NTPJ convert to hydrogen peroxide, which enhances intracellular ROS production, that play a major role in killing bacteria. Radicals from NTPJ disrupt mycobacterial cell wall integrity, leading to enhanced expression of genes related to thiol oxidoreductase, iron-homeostasis, and stress responses in Mtb cells, owing to a need for detoxification against $\mathrm{ROS}$ stress following exposure to the $\mathrm{OH}$ radicals.

\section{Acknowledgment}

We thank Minhye Cho (QIAGEN Korea Ltd.) and Yong Jae Kim (Zeiss Korea Ltd.) for the qRT-RCR analysis and confocal analysis. B.S., H.G.C., and H.W.S. supported the study. C.B.L., H.S.U., and H.J.K. wrote the manuscript, and designed the experiments. This study was supported by the National Research Foundation of Korea (NRF) funded by the Korean Government (MSIP) (2017R1A5A2015385), and partially by Brain Korea 21 PLUS Project for Medical Science, Chungnam National University School of Medicine.

\section{Conflict of Interest}

The authors have no financial conflicts of interest to declare.

\section{References}

1. Thomson R, Tolson C, Carter R, Coulter C, Huygens F, Hargreaves M. 2013. Isolation of nontuberculous mycobacteria (NTM) from household water and shower aerosols in patients with pulmonary disease caused by NTM. J. Clin. Microbiol. 51: 3006-3011.

2. Kohanski MA, Dwyer DJ, Hayete B, Lawrence CA, Collins JJ. 2007. A common mechanism of cellular death induced by bactericidal antibiotics. Cell 130: 797-810.

3. Piccaro G, Pietraforte D, Giannoni F, Mustazzolu A, Fattorini L. 2014. Rifampin induces hydroxyl radical formation in Mycobacterium tuberculosis. Antimicrob. Agents Chemother. 58: 7527-7533.

4. Vilchèze C, Hartman T, Weinrick B, Jacobs Jr WR. 2013. Mycobacterium tuberculosis is extraordinarily sensitive to killing by a vitamin C-induced Fenton reaction. Nat. Commun. 4: 1881.

5. Guo J, Li Z, Huang K, Li Y, Wang J. 2017. Morphology analysis of Escherichia coli treated with nonthermal plasma. J. Appl. Microbiol. 122: 87-96.

6. Uhm HS, Choi EH, Cho GS, Hwang DH. 2013. Influence of reactive oxygen species on the sterilization of microbes. Curr. Appl. Phys. 13: S30-S35.

7. Daeschlein G, Napp M, Majumdar A, Richter E, RüschGerdes S, Aly F, et al. 2017. In vitro killing of mycobacteria by low temperature atmospheric pressure plasma and dielectric barrier discharge plasma for treatment of tuberculosis. Clin. Plasma Med. 5: 1-7.

8. Lee NR, Park SH, Kim JY, Kim KY, Kim DY. 2018. Inactivation efficacy of a non-thermal atmospheric pressure plasma generator against Mycobacterium tuberculosis. Korean J. Healthc. Assoc. Infect. Control Prev. 23: 80-85.

9. Hong YC, Uhm HS. 2007. Air plasma jet with hollow electrodes at atmospheric pressure. Phys. Plasmas 14: 053503.

10. Hong YC, Kang WS, Hong YB, Yi WJ, Uhm HS. 2009. Atmospheric pressure air-plasma jet evolved from microdischarges: Eradication of E. coli with the jet. Phys. Plasmas 16: 123502.

11. Weltmann KD, Brandenburg R, von Woedtke T, Ehlbeck J, Foest R, Stieber M, et al. 2008. Antimicrobial treatment of heat sensitive products by miniaturized atmospheric pressure plasma jets (APPJs). J. Phys. D Appl. Phys. 41: 194008.

12. Lu X, Jiang Z, Xiong Q, Tang Z, Hu X, Pan Y. 2008. An 11 $\mathrm{cm}$ long atmospheric pressure cold plasma plume for applications of plasma medicine. Appl. Phys. Lett. 92: 081502. 
13. Flynn PB, Higginbotham S, Nid'a HA, Gorman SP, Graham WG, Gilmore BF. 2015. Bactericidal efficacy of atmospheric pressure non-thermal plasma (APNTP) against the ESKAPE pathogens. Int. J. Antimicrob. Agents 46: 101-107.

14. Xiaohu L, Feng H, Ying G, Jing Z, Jianjun S. 2013. Sterilization of Staphylococcus Aureus by an atmospheric non-thermal plasma jet. Plasma Sci. Technol 15: 439.

15. Mortazavi SM, Hosseinzadeh Colagar A, Sohbatzadeh F. 2016. The efficiency of the cold argon-oxygen plasma jet to reduce Escherichia coli and Streptococcus pyogenes from solid and liquid ambient. Iran. J. Med. Microbiol. 10: 19-30.

16. Uhm HS, Lim JP, Li SZ. 2007. Sterilization of bacterial endospores by an atmospheric-pressure argon plasma jet. Appl. Phys. Lett. 90: 261501.

17. Bansal-Mutalik R, Nikaido H. 2014. Mycobacterial outer membrane is a lipid bilayer and the inner membrane is unusually rich in diacyl phosphatidylinositol dimannosides. Proc. Natl. Acad. Sci. USA 111: 4958-4963.

18. Kolb JF, Mohamed AAH, Price RO, Swanson RJ, Bowman A, Chiavarini RL, et al. 2008. Cold atmospheric pressure air plasma jet for medical applications. Appl. Phys. Lett. 92: 241501.

19. Lee $\mathrm{CB}$, Na YH, Hong TE, Choi EH, Uhm HS, Baik KY, et al. 2014. Evidence of radicals created by plasma in bacteria in water. Appl. Phys. Lett. 105: 073702.

20. Kanazawa S, Kawano H, Watanabe S, Furuki T, Akamine S, Ichiki $\mathrm{R}$, et al. 2011. Observation of $\mathrm{OH}$ radicals produced by pulsed discharges on the surface of a liquid. Plasma Sources Sci. Technol. 20: 034010.

21. Akhtar S, Sarkar S, Mishra A, Sarkar D. 2011. A method to extract intact and pure RNA from mycobacteria. Anal. Biochem. 417: 286-288.

22. Siu GKH, Yam WC, Zhang Y, Kao RY. 2014. An upstream truncation of the furA-katG operon confers high-level isoniazid resistance in a Mycobacterium tuberculosis clinical isolate with no known resistance-associated mutations. Antimicrob. Agents Chemother. 58: 6093-6100.

23. Wu S, Howard ST, Lakey DL, Kipnis A, Samten B, Safi H, et al. 2004. The principal sigma factor sig $A$ mediates enhanced growth of Mycobacterium tuberculosis in vivo. Mol. Microbiol. 51: 1551-1562.

24. Christoph VS, Christian O. 2016. The application of cold atmospheric plasma in medicine: the potential role of nitric oxide in plasma-induced effects. Clin. Plasma Med. 4: 1-8.

25. Nambi S, Long JE, Mishra BB, Baker R, Murphy KC, Olive AJ, et al. 2015. The oxidative stress network of Mycobacterium tuberculosis reveals coordination between radical detoxification systems. Cell Host Microbe 17: 829-837.

26. Imaly JA. 2003. Pathway of oxidative damage. Annu. Rev. Microbiol. 57: 395-418.

27. Phaniendra A, Jestadi DB, Periyasamy L. 2015. Free radicals: properties, sources, targets, and their implication in various diseases. Indian. J. Clin. Biochem. 30: 11-26.

28. Wang TY, Libardo MDJ, Angeles-Boza AM, Pellois JP. 2017. Membrane oxidation in cell delivery and cell killing applications. ACS Chem. Biol. 12: 1170-1182.

29. Kumar N, Attri P, Choi EH, Uhm HS. 2015. Influence of water vapour with non-thermal plasma jet on the apoptosis of SK-BR-3 breast cancer cells. RSC Adv. 5: 14670-14677.

30. Joshi SG, Cooper M, Yost A, Paff M, Ercan UK, Fridman G, et al. 2011. Non-thermal dielectric-barrier discharge (DBD) Plasma-induced inactivation involves oxidative-DNA damage and membrane lipid peroxidation in Escherichia coli. Antimicrob. Agents Chemother. 55: 1053-1062.

31. Nasiri MJ, Haeili M, Ghazi M, Goudarzi H, Pormohammad A, Imani Fooladi AA, et al. 2017. New insights in to the intrinsic and acquired drug resistance mechanisms in mycobacteria. Front. Microbiol. 8: 681.

32. Imlay JA. 2008. Cellular defenses against superoxide and hydrogen peroxide. Annu. Rev. Biochem. 77: 755-776.

33. Winterbourn CC. 1995. Toxicity of iron and hydrogen peroxide: the Fenton reaction. Toxicol. Lett. 82: 969-974.

34. Rhee SG. 2006. $\mathrm{H}_{2} \mathrm{O}_{2}$, a necessary evil for cell signaling. Science 312: 1882-1883.

35. Dobrynin D, Friedman Gr, Friedman G, Fridman A. 2009. Physical and biological mechanisms of direct plasma interaction with living tissue. New. J. Phys. 11: 115020.

36. Baik KY, Kim YH, Ryu YH, Kwon HS, Park G, Uhm HS, et al. 2013. Feeding-gas effects of plasma jets on Escherichia coli in physiological solutions. Plasma Process. Polym. 10: 235-242.

37. Voskuil MI, Bartek IL, Visconti K, Schoolnik GK. 2011. The response of Mycobacterium tuberculosis to reactive oxygen and nitrogen species. Front. Microbiol. 2: 105.

38. Tyagi P, Dharmaraja AT, Bhaskar A, Chakrapani H, Singh A. 2015. Mycobacterium tuberculosis has diminished capacity to counteract redox stress induced by elevated levels of endogenous superoxide. Free Radic. Biol. Med. 84: 344-354.

39. Uhm HS. 2015. Generation of various radicals in nitrogen plasma and their behavior in media. Phys Plasmas. 22: 123506.

40. Uhm HS, Ki SH, Baik KY, Choi EH. 2018. Influence of oxygen on generation of reactive chemicals from nitrogen plasma jet. Sci. Rep. 8: 9318. 